\title{
Investigation of oil palm harvesting tools design and technique on work-related musculoskeletal disorders of the upper body
}

\author{
S. Mohamaddan ${ }^{\text {a,b,*, M.A. Rahman }}{ }^{\mathrm{b}}$, M. Andrew_Munot ${ }^{\mathrm{b}}$, S.J. Tanjong ${ }^{\mathrm{b}}$, B.M. Deros ${ }^{\mathrm{c}}$, S. \\ Z. Md Dawal ${ }^{\mathrm{d}}$, K. Case ${ }^{\mathrm{e}}$ \\ ${ }^{a}$ Department of Bioscience and Engineering, College of Systems Engineering and Science, Shibaura Institute of Technology, 337-8570 Saitama, Japan \\ ${ }^{\mathrm{b}}$ Department of Mechanical and Manufacturing, Faculty of Engineering, Universiti Malaysia Sarawak, 94300 Kota Samarahan, Sarawak, Malaysia

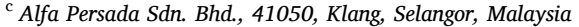 \\ d Department of Mechanical Engineering, Faculty of Engineering, University of Malaya, 50603, Kuala Lumpur, Malaysia \\ ${ }^{\mathrm{e}}$ Mechanical, Electrical and Manufacturing Engineering, Loughborough University, Leicestershire, LE11 3TU, United Kingdom
}

\section{A R T I C L E I N F O}

\section{Keywords:}

Fresh fruit bunch (FFB)

Work-related musculoskeletal disorders (WMSDs)

Rapid upper limb analysis (RULA)

Human musculoskeletal model analysis (HMMA)

\begin{abstract}
A B S T R A C T
The oil palm industry is one of the important sectors in Malaysia. The growth and development of this industry shows that Malaysia is the world second-largest oil palm producers. However, in the fresh fruit bunch (FFB) harvesting process, the harvesters are exposed to many types of work-related musculoskeletal disorders (WMSDs). The FFB harvesters tend to develop WMSDs especially the shoulders and trunk. Hence, it is important to identify the exposure levels, awkward postures and the reaction forces of muscle activity based on the posture and movement of the harvesters when using pole, chisel and loading spike during the harvesting process. The objective of this study was to investigate the effect of the design of oil palm FFB harvesting tools on WMSDs of the upper body. Rapid Upper Limb Analysis (RULA) was used to investigate and assess the exposure level on the harvester body during the harvesting process. The assessment showed that the shoulders and trunk have high exposure level and undergo awkward posture. Human Musculoskeletal Model Analysis (HMMA) was used to identify the reaction force exerted on the muscle during the FFB harvesting process. In this study, 4 muscles were analysed including Triceps, Biceps, Erector Spinae and Psoas Major. The highest reaction force of $16.36 \mathrm{~N}$ was found on the left triceps when handling a loading spike. In conclusion, it is important to address the risks by reviewing all possible aspects that contribute to the WMSDs and interventions on the tool design, task and working shifts may be required.
\end{abstract}

\section{Introduction}

\subsection{Background}

In developing countries such as Malaysia, the agriculture sector specifically the oil palm industry, is important to the nation's growth (Jin et al., 2001). Hence, improving the agricultural productivity of the oil palm sector is important for economic expansion and development (Doss, 2006). Oil palm is potentially one of the best solutions to overcome the increasing demands for food and energy. In order to expand the wellspring of oil palm, the fresh fruit bunch (FFB) harvesting process must be productive and beneficial (Yusof, 2014). However, there are many work-related musculoskeletal disorders (WMSDs) issues among the FFB harvesters that may cause productivity loss ( $\mathrm{Ng}$ et al., 2014). WMSDs are one of the most widely discussed topics in the field of labor health (Chen and Ou, 2020). In oil palm harvesting process, the FFB harvesters undergo fatigue and discomfort at their body parts where swelling, pain in the joints and tingling happens (Halim et al., 2011). Comprehensive data is needed by designers to design the tools that can prevent WMSDs with zero impact on quality and productivity. Furthermore, the FFB harvesters still face WMSDs issues even though machines are used during FFB harvesting process (Syazwani et al., 2015). The work elements such as walking, standing and bending are unavoidable and have a negative impact on the FFB harvester's health

\footnotetext{
* Corresponding author. Department of Bioscience and Engineering, College of Systems Engineering and Science, Shibaura Institute of Technology, 337-8570 Saitama, Japan.

E-mail addresses: mshahrol@shibaura-it.ac.jp (S. Mohamaddan), im.aliffrahman@gmail.com (M.A. Rahman), ammagdal@unimas.my (M. Andrew_Munot), jtshirley@unimas.my (S.J. Tanjong), babaderos@gmail.com (B.M. Deros), sitizawiahmd@um.edu.my (S.Z. Md Dawal), k.case@lboro.ac.uk (K. Case).
} 